\title{
Le Vieil-Évreux - Les remparts : le théâtre
}

\section{Filipe Ferreira}

\section{OpenEdition \\ Journals}

Édition électronique

URL : http://journals.openedition.org/adlfi/16608

ISSN : 2114-0502

Éditeur

Ministère de la culture

\section{Référence électronique}

Filipe Ferreira, "Le Vieil-Évreux - Les remparts : le théâtre », ADLFI. Archéologie de la France -

Informations [En ligne], Haute-Normandie, mis en ligne le 18 février 2016, consulté le 19 avril 2019.

URL : http://journals.openedition.org/adlfi/16608

Ce document a été généré automatiquement le 19 avril 2019

(c) Ministère de la Culture et de la Communication, CNRS 


\title{
Le Vieil-Évreux - Les remparts : le théâtre
}

\author{
Filipe Ferreira
}

Code INSEE commune : 27684

Lien Atlas (MCC) :

http://atlas.patrimoines.culture.fr/atlas/trunk/index.php?

ap_theme=DOM_2.01.02\&ap_bbox=1.177;48.985;1.250;49.017

1 La campagne de fouilles dirigée sur le théâtre du Vieil-Évreux en 2013 a eu pour objectif de mieux saisir l'évolution du plateau scénique. La campagne précédente nous avait déjà permis d'appréhender différentes phases de construction mais le matériel datant étant rare, la fourchette chronologique proposée restait relativement large. Cette année, le sondage a été prolongé vers le nord de l'estrade scénique, afin de préciser non seulement la chronologie relative de ces structures mais aussi la nature de ces constructions.

D'emblée, soulignons que la plupart des études n'ont pas encore été menées à terme et que les indices chronologiques restent encore de l'ordre de l'hypothèse. Néanmoins, il est possible de proposer une chronologie relative de ces constructions et de les rattacher aux différentes phases déjà observées au sein du théâtre du Vieil-Évreux.

Le premier état de la scène correspond probablement au premier théâtre connu, elle mesure environ $9 \mathrm{~m}$ de longueur sur $4 \mathrm{~m}$ de largeur. Le bâtiment d'arrière-scène correspondant mesure environ $5 \mathrm{~m}$ de longueur et 3,70 $\mathrm{m}$ de largeur. Ses fondations sont d'ailleurs reliées au premier état du mur de scène. Cette première estrade subit ensuite un faible agrandissement de $1 \mathrm{~m}$ de largeur. Par la suite, probablement lors de la construction du second théâtre, la scène est agrandie et mesure près de $22 \mathrm{~m}$ de longueur sur 6,30 m de largeur. Ces modifications ont également entraîné la reconstruction du bâtiment d'arrière-scène. Les matériaux de construction du premier état ont été soigneusement récupérés et les accès qui étaient disposés de part et d'autre de la première scène ont été supprimés. 
Enfin, l'espace scénique est remanié une dernière fois. Ces modifications ont eu un impact important sur l'ensemble du monument, avec pour conséquence l'exhaussement de la cavea. Le goût pour les jeux de l'arène a nécessité le surcreusement de l'orchestra. Le mur avant du plateau scénique a donc été détruit puis reconstruit et prolongé d'une part pour rattraper le niveau de sol du nouvel espace de représentation, d'autre part pour supprimer l'espace ouvert situé entre le mur délimitant l'orchestra et les murs latéraux du plateau scénique antérieur. Les changements observés les années précédentes à la hauteur de la cavea (rehaussement des gradins, consolidation des murs externes et des accès, modification des niveaux de circulation) appartiennent donc à un vaste chantier de reconstruction concernant probablement l'ensemble du monument.

Quelques traces d'occupation datant de la période médiévale au XIX ${ }^{\mathrm{e}} \mathrm{s}$. ont été observées. L'ensemble reste cependant très perturbé par les fouilles anciennes et les anciens chablis. La mise en place du parcellaire au $\mathrm{XIX}^{\mathrm{e}} \mathrm{s}$. et au début du $\mathrm{Xx}^{\mathrm{e}} \mathrm{s}$. a fortement endommagé le monument, relativement bien préservé jusque-là.

6 Le théâtre du Vieil-Évreux s'ajoute donc à ce groupe d'édifice de spectacles encore peu connus en Gaule, et regroupant plusieurs théâtres de taille moyenne, dont l'orchestra est modifiée en arène, ou comme ici, simplement "surcreusée », pour permettre la tenue de combats. La prochaine campagne d'étude sera essentiellement consacrée au matériel archéologique, et notamment aux nombreux enduits peints provenant du mur d'orchestra ainsi que du mobilier céramique, relativement rare jusqu'ici.

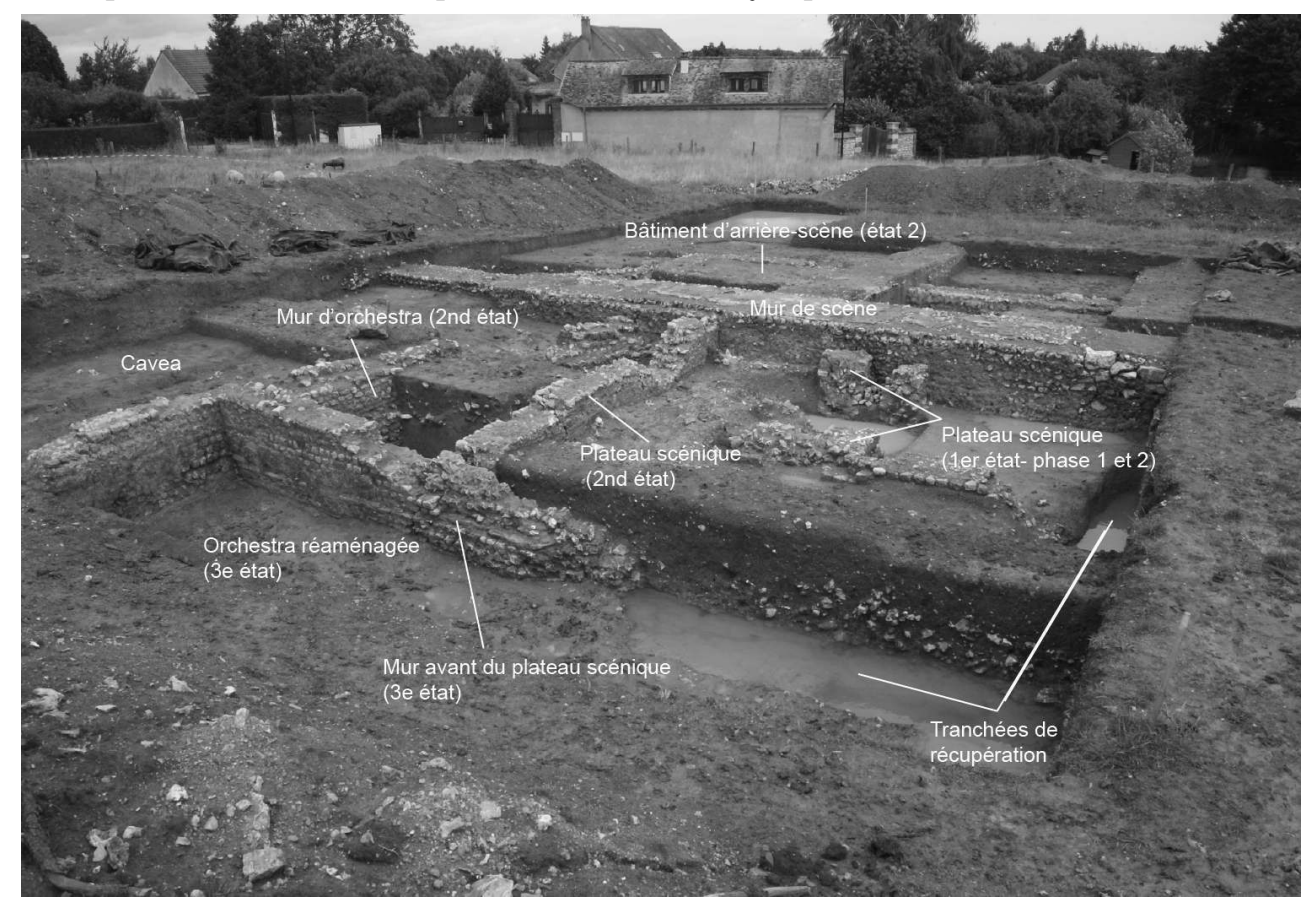

Fig.01 :

Moitié nord du plateau scénique fouillée en 2013

F. Ferreira 
INDEX

Index chronologique : Antiquité

Mots-clés : ville-sanctuaire, théâtre, édifice de spectacle, cavea

Index géographique : Normandie, Eure (27), Le Vieil-Évreux

operation Fouille programmée (FP)

\section{AUTEURS}

\section{FILIPE FERREIRA}

Université Paris-Sorbonne 